\title{
Estimating direct effects of parental occupation on Spaniards' health by birth cohort
}

\author{
Jaime Pinilla', Beatriz G. Lopez-Valcarcel ${ }^{1}$ and Rosa M. Urbanos-Garrido²*
}

\begin{abstract}
Background: Social health inequalities in adult population are partly due to socioeconomic circumstances in childhood. A better understanding of how those circumstances affect health during adulthood may improve the opportunities for reducing health disparities. The objective of this study is to investigate the effect of parental socioeconomic status, which is proxied by occupation, on adult Spaniards' health by birth cohort. The analysis will allow checking not only the direct impact of parental occupation on their offspring's health, but also whether inherited inequality has been reduced over time.
\end{abstract}

Methods: We use data from the Bank of Spain's Survey of Household Finances on Spanish households from 2002 to 2008. Sequential models were used to estimate the influence of the father's and mother's occupation on their offspring's health, trying to disentangle direct from indirect effects. With a sample of 26,832 persons we consider effects for four different cohorts by birth periods ranging from 1916 to 1981.

Results: The results show that parental occupation has a significant direct impact on individuals' health $(p<0.01)$. The effect of father's occupation exceeds that of mother's. For those born before 1936, the probability of reporting a good health status ranges from 0.31 (95\% confidence interval (Cl) 0.14-0.48), when fathers were classified as unskilled elementary workers, to $0.98(95 \% \mathrm{Cl} 0.98-0.99)$ when they were managers or mid-level professionals. For those born during the period 1959-1975, those probabilities are 0.49 (95\% Cl 0.39-0.59) and 0.97 (95\% Cl 0.96-0.98), respectively. Therefore, health inequalities linked to parental socioeconomic status have been noticeably reduced, although discrimination against unskilled workers persists over time.

Conclusions: Great progress has been made in the health area during the twentieth century, so that the impact of parental socioeconomic status on individuals' health has been significantly tempered for those at the bottom of the social scale. However, more efforts focused on the improvement of living conditions for most socioeconomically disadvantaged are needed in order to further reduce social inequalities in health.

Keywords: Intergenerational transmission, Self-assessed health, Socioeconomic status, Cohort effects

\section{Background}

It has been well established that social health inequalities in adult population are partly due to socioeconomic circumstances in childhood [1-22]. Two basic hypotheses explain the relationship between social status in early life and adults' health. According to the life course hypothesis, social background directly influences health in adulthood

\footnotetext{
* Correspondence: urbanos@ccee.ucm.es

${ }^{2}$ Department of Public Finance, School of Economics, Complutense

University of Madrid, Campus de Somosaguas s/n, 28223 Pozuelo de Alarcón,

Spain

Full list of author information is available at the end of the article
}

since those with inferior living conditions during childhood and adolescence are more likely to experience poor health later in life $[2,4-6,16,20,23]$. Moreover, the pathway hypothesis suggests that parental socioeconomic circumstances indirecty influence health in adulthood through the transmission of socioeconomic status (SES) and the investment in children's human capital [7, 8, 12, 17, 22].

The evidence of how parental SES affect Spaniards' health is scarce. Tubeuf and Jusot [11] and Bricard et al. [18] show how parents' social status and initial conditions in childhood influence adults' health in Spain and 
some other European countries, although they do not distinguish between direct and indirect effects. They also find that the contribution of family background to social health inequality in Spain is more important than the contribution of individual status. Flores and Kalwij [21] also prove for a group of European countries including Spain that favourable early life circumstances are associated with a higher level of education and also with better health in adulthood, even when education is controlled for, thus showing the existence of both direct and indirect effects of parental status on health. These previous studies use data from the Survey of Health, Aging, and Retirement in Europe (SHARE), which only includes adults in pre-retirement age. This paper uses a different database, the Spanish Survey of Household Finances (EFF by its Spanish acronym), which represents the entire adult population of Spaniards. Also, this dataset allows checking if effects of parental SES on individuals' health significantly differ by cohort. To the best of our knowledge, this issue has not been previously addressed.

The objective of this study is to investigate the effect of parental socioeconomic status, which is proxied by occupation, on adult Spaniards' health by birth cohort. The analysis will allow checking not only the direct impact of parental occupation on their offspring's health, but also whether inherited inequality has been reduced over time. A better understanding of how social circumstances in childhood affect health during adulthood may improve the opportunities for reducing health disparities. Furthermore, the research on whether the transmission of social inequalities has been tempered across the twentieth century will help us to determine the redistributive efficacy of Spanish public policies over time.

\section{Methods}

\section{Dataset and sample definition}

The EFF is a survey undertaken by the Bank of Spain that is included in the Spanish National Statistics Plan. There have been four waves: the first started in 2002 (data collected in 2002 and 2003), the second in 2005 (2005-2006), the third in 2008 (2008-2009) and the most recent in 2011. Each wave surveyed about 5500 households, representing approximately 15,000 people, which accounts for a representative sample of the Spanish population. In our analysis, we pooled the data from EFF2002, EFF2005 and EFF2008. Previously, we performed tests of homogeneity to check for wave effects. We excluded data from 2011, as the effects of the economic crisis on income and wealth, as well as on health measures, might bias the results of the study. This database is quite rich in economic information about families, including those with a privileged socioeconomic status.
The EFF questionnaire mainly provides economic information about income, net wealth and consumption at the household level, but it also includes individual sociodemographic characteristics such as age, sex, educational level, occupational category, self-assessed health (SAH) and past circumstances associated with parents' social status for the household reference person and for his/ her partner. In particular, the EFF includes information about occupational category that parents have (or had for most of their working lives). This data thus allows us to link individuals' SAH, not only with their current socioeconomic situation, but also with their socioeconomic background, since parental occupation may be a good proxy of the childhood socioeconomic group.

Our sample was limited to the household reference person (usually the person in the household who handles financial issues) and his/her partner, because in the questionnaire only these individuals are asked for information about their parents. We have truncated the sample to the age interval $28-86$ at the time of the survey. People younger than 28 have been excluded after we developed a joinpoint analysis [24] of the rates of people reporting bad health at each age. Also, individuals aged over 86 have been ignored since they show a high variability in their self-assessed health.

\section{Empirical model specification and estimation method}

We are interested in quantifying the direct impact on adults' health of childhood circumstances and social background, given by their parents' occupation. However, as we mentioned before the relationship between parental situation and an individual's health may take place through indirect channels, as parents' SES may influence offspring's educational level and occupation. Therefore, the econometric method we adopt to estimate the direct effects of parental occupation on health controls for indirect effects via education and occupation. Following Trannoy et al. [10], we successively estimated three discrete choice equations, where dependent variables are educational level, occupational category and health, respectively. From the first two discrete choice equations we calculate the 'generalized residuals' $\left(U_{s}\right)$, which are used as proxies for unobservable variables in the respective next equations. The final model is then represented by Eqs. (1) to (3).

$$
\begin{aligned}
& \text { Education }=f_{1}\left(D, C, T, C^{*} T, u_{1}\right) \\
& \text { Occupation }=f_{2}\left(D, C, T, C^{*} T, \widehat{u_{1}}, u_{2}\right) \\
& \text { Health }=f_{3}\left(D, E, C, T, C^{*} T, \widehat{u_{1}}, \widehat{u_{2}}, u_{3}\right)
\end{aligned}
$$

where D represents the vector of demographic characteristics, $\mathrm{C}$ the childhood circumstances, $\mathrm{T}$ the time variables (birth cohort), and $\mathrm{E}$ the individual economic status. 
According to Eq. (1), educational attainment depends, besides demographic characteristics, on childhood circumstances (that will be proxied by father's and mother's occupation) and time variables. Since one of our aims is to analyze if the dynastic effect varies over time, we also include in all the equations cohort dummies and interaction variables between parental occupation and cohorts. In Eq. (2), personal occupational category is again regressed on demographic variables and parents' occupation legacy, besides on cohort variables. We also include the generalized residual of Eq. (1). The term $\widehat{u_{1}}$ indicate the portion of personal educational attainment which is not attributable to parental circumstances or demographic factors. Finally, Eq. (3) specifies that health depends, besides demographic characteristics, on the current economic situation of the household (E), on the chilhood circumstances and cohort variables as well as on education and occupation, which have been previously purged of parental influence through generalized residuals ( $\widehat{u_{1}}$ and $\left.\widehat{u_{2}}\right)$. Thus, the coefficients of parental variables in Eq. (3) attempt to measure the direct effect of the father's and mother's occupation on the descendant's health.

As the interaction effects are conditional on the values of the predictor variable, even if we observe a significant coefficient the effect may be statistically insignificant across all values of the regressor [25]. Thus, we calculated the adjusted probabilities for interaction terms in Eqs. (1)-(3). The probabilities have been evaluated for the observed values of the sample individuals, and then we calculated the average (Average Partial Effects, APE). We also estimated the $95 \%$ CI for each probability by delta method. In the estimation process we have incorporated the weight of each individual according to the sample design.

Equation (1) is estimated as an ordered probit model since, as we explain in the next subsection, we define four categories for educational level. Moreover, Eqs. (2) and (3) are estimated as binary probits. Due to the impossibility of obtaining a non-arbitrary ranking of social status [10], we only distinguish in Eq. (2) high from low occupational status. Finally, we used the approximate likelihood test of equality of coefficients across response categories to test the appropriateness of using a binary dependent variable in Eq. (3), instead of an ordinal variable. Since the non-linear specification does not allow direct estimation of the residuals $\widehat{u_{1}}$ and $\widehat{u_{2}}$, we calculated the generalized residuals, which correspond to the conditional expected value of residuals given the outcome [26].

\section{Definition of variables}

Dependent variables in Eqs. (1) to (3) have been defined as follows. Firstly, educational level has been categorized into four groups: 'illiterate and primary education,' 'lower secondary schooling, 'higher secondary schooling' and 'specialised vocational training and university degree'. The occupational category has been defined as a dummy variable taking a value of 1 for high occupational status (top managers and mid-level professionals, ISCO 1-4), and 0 otherwise. Finally, SAH is used as a proxy for health stock, which was assessed through a single question: 'How is your health in general?', with five possible answers: very good, good, acceptable, poor and very poor. These five categories have been reclassified in two by defining a dummy variable taking value of 1 for good or very good health, and 0 for fair, poor or very poor health. We will refer to these categories as 'good' and 'bad' health throughout the text.

The vector $\mathrm{D}$ of demographic characteristics includes age and sex. Childhood circumstances $(C)$ have been proxied by parental occupation, since it is the only variable included in the EFF about the social background of individuals during their early lifes. Occupations are described with the one-digit ISCO (International Standard Classification of Occupations), which distinguishes ten main groups of occupations, plus one for homemakers.

Fathers' occupations are classified into five groups: (1) 'top level managers in the public or private sector, technicians and professionals, intellectuals or scientists' (ISCO 1+2); (2) 'supporting technicians and professionals, administrative staff' (ISCO $3+4$ ); (3) 'armed forces' (ISCO 10); (4) 'skilled workers in service, agriculture, fishing, manufacturing, construction or mining industries' (ISCO 5-8); and (5) 'unskilled elementary workers' (ISCO 9). As there are not any homemaker fathers in the sample, that category is not defined. Due to low frequencies in some occupational categories, we distinguished only three categories for mothers in our final models: (1) top and middle-level professionals (ISCO 1-4); (2) other workers, including skilled and elementary occupations (ISCO 5-10); and (3) homemakers.

Individuals in the sample, aged 28-86 at the time of the survey, were born from 1916 to 1981 . We have defined our $\mathrm{T}$ variable by distinguishing four cohort categories related to the Spanish political and economic context: 1) pre-war cohort, before 1936; 2) war and post-war cohort, born in 1937-1958; 3) Stabilization Plan -Franco's 1959 economic reform plan- cohort, born in 1959-1975; and 4) democracy cohort, born after 1975 (since Franco died in November 1975).

Finally, the current economic situation of individuals (E) is measured by two variables: family income and family wealth. We calculated quartiles of household equivalent income and wealth by using the OECD equivalence scale (which assigns a value 1 to the household head, 0.7 to each additional adult and 0.5 to each child). The income variable is obtained as the sum of labour and non-labour incomes for all members of the 
household. The net wealth variable is calculated from the value of a household's real assets: main residence, other real estate properties, jewelry, works of arts, antiques, and the value of businesses related to self-employment. The first quartile also includes those households with negative wealth (net debt).

\section{Results}

Table 1 shows the descriptive statistics of the estimation sample (frequency distributions for discrete variables, mean and standard deviation for continuous ones and for income and wealth quartiles). Standard error estimates are produced using Taylor linearization. The number of individuals in the sample who are the household's reference person or his/her partner is 28,980 . After removing observations with missing data, our estimation sample has 26,832 individuals aged $28-86$. All the calculations have been made by using the sampling weights.

Table 2 displays the estimated coefficients and their standard errors for Eqs. (1)-(3), except those corresponding

Table 1 Definition of variables and descriptive statistics

\begin{tabular}{|c|c|c|c|}
\hline Variables & Recoded variables & Definition & $\begin{array}{l}\text { Mean }^{\mathrm{a}} \\
(n=26,832)\end{array}$ \\
\hline \multicolumn{4}{|l|}{ Dependent variables } \\
\hline Educational level & Education $^{\mathrm{b}}$ & $\begin{array}{l}1 \text { if illiterate or primary education, } 2 \text { if lower secondary schooling, } \\
3 \text { if higher secondary schooling, } 4 \text { if specialized vocational training } \\
\text { or university degree }\end{array}$ & $\begin{array}{l}\text { (1) } 40.02 \% \\
\text { (2) } 18.42 \% \\
\text { (3) } 15.34 \% \\
\text { (4) } 26.22 \%\end{array}$ \\
\hline Occupational status & Top_workers & 1 if manager, mid-level professional or supporting worker, 0 otherwise & $14.20 \%$ \\
\hline Self-assessed health & $\mathrm{SAH}$ & 1 if very good or good health is reported, 0 otherwise & $79.50 \%$ \\
\hline \multicolumn{4}{|l|}{ Independent variables } \\
\hline Age & Age & Age in years & $45.99(14.52)$ \\
\hline Sex & Female & 1 if female, 0 otherwise & $52.44 \%$ \\
\hline \multirow[t]{4}{*}{$\begin{array}{l}\text { Equivalent household } \\
\text { income }\end{array}$} & $\begin{array}{l}\text { Income_Q1 } \\
\text { (omitted category) }\end{array}$ & 1 if the person belongs to the $1^{\text {st }}$ income quartile, 0 otherwise & $5460.38(40.80)$ \\
\hline & Income_Q2 & 1 if the person belongs to the $2^{\text {nd }}$ income quartile, 0 otherwise & $10284.62(40.76)$ \\
\hline & Income_Q3 & 1 if the person belongs to the $3^{\text {rd }}$ income quartile, 0 otherwise & $16746.49(72.10)$ \\
\hline & Income_Q4 & 1 if the person belongs to the $4^{\text {th }}$ income quartile, 0 otherwise & $37524.9(693.05)$ \\
\hline \multirow[t]{4}{*}{$\begin{array}{l}\text { Equivalent net household } \\
\text { wealth }^{c}\end{array}$} & $\begin{array}{l}\text { Wealth_Q1 } \\
\text { (omitted category) }\end{array}$ & 1 if the person belongs to the $1^{\text {st }}$ wealth quartile, 0 otherwise & $19014.56(492.31)$ \\
\hline & Wealth_Q2 & 1 if the person belongs to the $2^{\text {nd }}$ wealth quartile, 0 otherwise & $77213.64(629.88)$ \\
\hline & Wealth_Q3 & 1 if the person belongs to the $3^{\text {rd }}$ wealth quartile, 0 otherwise & $167070.5(1755.69)$ \\
\hline & Wealth_Q4 & 1 if the person belongs to the $4^{\text {th }}$ wealth quartile, 0 otherwise & $540931.7(21606.4)$ \\
\hline \multirow[t]{5}{*}{ Father occupation } & $\begin{array}{l}\text { F_Manager } \\
\text { (omitted category) }\end{array}$ & 1 if manager or mid-level professional (ISCO $1+2)$, 0 otherwise & $10.22 \%$ \\
\hline & F_Supporting & 1 if supporting worker (ISCO $3+4)$, 0 otherwise & $15.70 \%$ \\
\hline & F_ArmedF & 1 if member of armed forces (ISCO 10), 0 otherwise & $2.20 \%$ \\
\hline & F_Skilled & 1 if skilled worker (ISCO 5-8), 0 otherwise & $49.65 \%$ \\
\hline & F_Unskilled & 1 if unskilled elementary worker (ISCO 9), 0 otherwise & $22.23 \%$ \\
\hline \multirow[t]{3}{*}{ Mother occupation } & $\begin{array}{l}\text { M_Top_worker } \\
\text { (omitted category) }\end{array}$ & 1 if manager, mid-level professional or supporting worker, 0 otherwise & $6.74 \%$ \\
\hline & M_Elem_worker & 1 if elementary worker (skilled or unskilled), 0 otherwise & $12.54 \%$ \\
\hline & M_Homemaker & 1 if homemaker, 0 otherwise & $80.73 \%$ \\
\hline \multirow[t]{4}{*}{ Cohort } & $\begin{array}{l}\text { Pre-war (omitted } \\
\text { category) }\end{array}$ & 1 if born 1916-1936, 0 otherwise & $17.53 \%$ \\
\hline & War \& post-war & 1 if born 1937-1958, 0 otherwise & $37.03 \%$ \\
\hline & Ec_stabilization & 1 if born 1959-1975, 0 otherwise & $41.18 \%$ \\
\hline & Democracy & 1 if born 1976-1981, 0 otherwise & $4.27 \%$ \\
\hline
\end{tabular}

${ }^{a}$ Weights are applied to the descriptive statistics. \% in categorical variables, mean and linearized std. error for the continuous ones. ${ }^{\mathrm{b}}$ We report the percentages

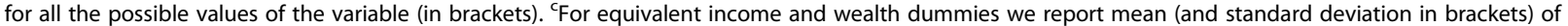
income and wealth levels for each quartile 
Table 2 Results of the estimation (without interaction terms). Equations (1)-(3)

\begin{tabular}{|c|c|c|c|}
\hline Explanatory variables & $\begin{array}{l}\text { Eq. (1) } \\
\text { Probability of having a higher educational } \\
\text { level. Ordered probit estimates }\end{array}$ & $\begin{array}{l}\text { Eq. (2) } \\
\text { Probability of having a top occupation. } \\
\text { Binary probit estimates }\end{array}$ & $\begin{array}{l}\text { Eq. (3) } \\
\text { Probability of reporting good health. } \\
\text { Binary probit estimates }\end{array}$ \\
\hline Age & $-0.039^{* * *}(0.002)$ & $-0.005^{*}(0.003)$ & $-0.061^{* * *}(0.005)$ \\
\hline Female & $-0.159^{* * *}(0.017)$ & $-0.450^{* * *}(0.028)$ & $-1.490^{* * *}(0.379)$ \\
\hline \multicolumn{4}{|l|}{ Father occupation } \\
\hline F_Supporting & $0.169(0.112)$ & $-0.799^{* * *}(0.110)$ & $-2.733^{* * *}(0.743)$ \\
\hline F_ArmedF & $0.308(0.155)$ & $-0.713^{* * *}(0.180)$ & $-2.419^{* * *}(0.677)$ \\
\hline F_Skilled & $-0.790 * * *(0.102)$ & $-1.343^{* * *}(0.103)$ & $-4.494^{* * *}(1.188)$ \\
\hline F_Unskilled & $-1.222^{* * *}(0.116)$ & $-1.591^{* * *}(0.117)$ & $-5.276^{* * *}(1.382)$ \\
\hline \multicolumn{4}{|l|}{ Mother occupation } \\
\hline M_Elem_worker & $-0.628^{* * *}(0.170)$ & $-0.425^{* *}(0.175)$ & $-1.483^{* * *}(0.413)$ \\
\hline M_Homemaker & $-0.446^{* * *}(0.148)$ & $-0.412^{* * *}(0.145)$ & $-1.258^{* * *}(0.398)$ \\
\hline \multicolumn{4}{|l|}{ Cohort } \\
\hline War \& post-war & $-0.056(0.173)$ & $-0.233(0.181)$ & $-0.825^{* * *}(0.275)$ \\
\hline Ec_stabilization & $-0.270(0.180)$ & $-0.136(0.199)$ & $-0.776^{* * *}(0.247)$ \\
\hline Democracy & $-0.577(0.368)$ & $0.070(0.412)$ & $0.045(0.437)$ \\
\hline \multicolumn{4}{|l|}{ Current economic status } \\
\hline $2^{\text {nd }}$ Quartile Income & & & $0.071^{*}(0.037)$ \\
\hline $3^{\text {rd }}$ Quartile Income & & & $0.249^{* * *}(0.042)$ \\
\hline $4^{\text {th }}$ Quartile Income & & & $0.375^{* * *}(0.056)$ \\
\hline $2^{\text {nd }}$ Quartile net wealth & & & $0.153^{* * *}(0.038)$ \\
\hline $3^{\text {rd }}$ Quartile net wealth & & & $0.174^{* * *}(0.043)$ \\
\hline $4^{\text {th }}$ Quartile net wealth & & & $0.295^{* * *}(0.057)$ \\
\hline \multicolumn{4}{|l|}{ Residuals } \\
\hline Equation [1] & & $0.083^{* * *}(0.027)$ & $0.229 * * *(0.084)$ \\
\hline Equation [2] & & & $2.737^{* * *}(0.754)$ \\
\hline$\%$ correct predictions & $73.80 \%$ & $80.96 \%$ & $76.79 \%$ \\
\hline$N^{\circ}$ observations & 26,832 & 26,832 & 26,832 \\
\hline
\end{tabular}

${ }^{* * *} p<0.01,{ }^{* *} p<0.05,{ }^{*} p<0.1$

to interaction terms with cohort and fathers'/mothers' occupation. In Table 3 we show the adjusted probabilities for interaction terms in Eqs. (1)-(3) and their 95\% CI.

The estimated coefficients for demographic variables (Table 2) are mostly highly significant, and they have the expected sign. Age significantly reduces the probability of having a higher educational level and reporting good or very good health, and it also seems to have a significant -although lower- influence on the probability of being at the top of the occupational ranking. Furthermore, women are less likely than men to reach a high educational attainment, to have top occupations or to report good health.

Parental occupation is very relevant across the three equations, and the effect of father's occupation exceeds that of mother's. Compared to those people who have a manager or mid-level professional father, having a father categorized as an skilled or unskilled elementary worker significantly reduces the probability of attaining a higher educational level, having a top occupation or reporting good health. Also, those whose mother is a housewife or an elementary worker tend to report a lower educational level, a lower occupational status and a worse health, compared to people whose mother occupies a managerial position, is a mid-level proffesional or a supporting worker.

Cohort variables do not seem to play a significant role in the estimation of educational and occupational attainments. However, people born during the period 19361975 tend to report significantly worse health than those born in the pre-war cohort.

Besides, the current economic situation of the household, which is only included in Eq. (3) - probability of reporting good health-, is highly significant. The higher the quartile of equivalent household income or wealth, the greater the odds of being healthy. Also, non-observable variables 
Table 3 Adjusted predictions of interaction terms in Equations (1)-(3): probability evaluated at the means

\begin{tabular}{|c|c|c|c|c|}
\hline & Pre-war & War \& post-war & Ec_stabilization & Democracy \\
\hline \multicolumn{5}{|c|}{ Probability of having a higher educational level (Eq. (1)) } \\
\hline \multicolumn{5}{|l|}{ Fathers'occupation } \\
\hline F_Man\&Prof & $0.42(0.35 ; 0.48)$ & $0.53(0.49 ; 0.57)$ & $0.44(0.41 ; 0.48)$ & $0.29(0.13 ; 0.44)$ \\
\hline F_Supporting & $0.47(0.42 ; 0.53)$ & $0.47(0.44 ; 0.51)$ & $0.37(0.34 ; 0.40)$ & $0.27(0.19 ; 0.35)$ \\
\hline F_ArmedF & $0.52(0.43 ; 0.61)$ & $0.46(0.39 ; 0.53)$ & $0.38(0.31 ; 0.46)$ & $0.28(0.10 ; 0.46)$ \\
\hline F_Skilled & $0.19(0.15 ; 0.22)$ & $0.21(0.19 ; 0.23)$ & $0.22(0.21 ; 0.24)$ & $0.21(0.16 ; 0.25)$ \\
\hline F_Unskilled & $0.10(0.07 ; 0.13)$ & $0.12(0.10 ; 0.14)$ & $0.13(0.11 ; 0.14)$ & $0.09(0.05 ; 0.12)$ \\
\hline \multicolumn{5}{|l|}{ Mothers'occup. } \\
\hline M_Top_worker & $0.37(0.28 ; 0.45)$ & $0.29(0.24 ; 0.34)$ & $0.28(0.25 ; 0.31)$ & $0.27(0.19 ; 0.36)$ \\
\hline M_Elem_worker & $0.20(0.16 ; 0.25)$ & $0.24(0.21 ; 0.27)$ & $0.23(0.20 ; 0.26)$ & $0.15(0.10 ; 0.20)$ \\
\hline M_Homemaker & $0.25(0.21 ; 0.28)$ & $0.28(0.26 ; 0.29)$ & $0.25(0.24 ; 0.27)$ & $0.20(0.16 ; 0.24)$ \\
\hline \multicolumn{5}{|c|}{ Probability of having a top occupation (Eq. (2)) } \\
\hline \multicolumn{5}{|l|}{ Fathers'occupation } \\
\hline F_Man\&Prof & $0.42(0.34 ; 0.50)$ & $0.43(0.39 ; 0.48)$ & $0.42(0.37 ; 0.47)$ & $0.40(0.16 ; 0.64)$ \\
\hline F_Supporting & $0.17(0.12 ; 0.21)$ & $0.24(0.20 ; 0.27)$ & $0.18(0.14 ; 0.21)$ & $0.13(0.04 ; 0.21)$ \\
\hline F_ArmedF & $0.19(0.10 ; 0.28)$ & $0.23(0.17 ; 0.30)$ & $0.23(0.14 ; 0.32)$ & $0.35(0.08 ; 0.79)$ \\
\hline F_Skilled & $0.07(0.04 ; 0.09)$ & $0.10(0.09 ; 0.12)$ & $0.10(0.09 ; 0.12)$ & $0.08(0.04 ; 0.14)$ \\
\hline F_Unskilled & $0.04(0.02 ; 0.06)$ & $0.06(0.05 ; 0.08)$ & $0.06(0.05 ; 0.08)$ & $0.02(0.01 ; 0.04)$ \\
\hline \multicolumn{5}{|l|}{ Mothers'occup. } \\
\hline M_Top_worker & $0.19(0.12 ; 0.26)$ & $0.18(0.13 ; 0.22)$ & $0.20(0.14 ; 0.25)$ & $0.21(0.11 ; 0.32)$ \\
\hline M_Elem_worker & $0.11(0.07 ; 0.14)$ & $0.14(0.11 ; 0.17)$ & $0.13(0.09 ; 0.16)$ & $0.08(0.02 ; 0.17)$ \\
\hline M_Homemaker & $0.11(0.09 ; 0.13)$ & $0.15(0.14 ; 0.17)$ & $0.14(0.12 ; 0.15)$ & $0.11(0.06 ; 0.16)$ \\
\hline \multicolumn{5}{|c|}{ Probability of reporting a good health status (Eq. (3)) } \\
\hline \multicolumn{5}{|l|}{ Fathers'occupation } \\
\hline F_Man\&Prof & $0.98(0.98 ; 0.99)$ & $0.98(0.97 ; 0.99)$ & $0.97(0.96 ; 0.98)$ & - \\
\hline F_Supporting & $0.84(0.81 ; 0.86)$ & $0.90(0.88 ; 0.92)$ & $0.85(0.83 ; 0.87)$ & - \\
\hline F_ArmedF & $0.87(0.83 ; 0.90)$ & $0.90(0.87 ; 0.91)$ & $0.89(0.86 ; 0.92)$ & - \\
\hline F_Skilled & $0.51(0.42 ; 0.61)$ & $0.68(0.65 ; 0.69)$ & $0.68(0.65 ; 0.71)$ & - \\
\hline F_Unskilled & $0.31(0.14 ; 0.48)$ & $0.47(0.35 ; 0.54)$ & $0.49(0.39 ; 0.59)$ & - \\
\hline \multicolumn{5}{|l|}{ Mothers'occup. } \\
\hline M_Top_worker & $0.91(0.84 ; 0.98)$ & $0.87(0.81 ; 0.93)$ & $0.92(0.85 ; 0.98)$ & - \\
\hline M_Elem_worker & $0.55(0.43 ; 0.67)$ & $0.72(0.70 ; 0.76)$ & $0.68(0.63 ; 0.74)$ & - \\
\hline M_Homemaker & $0.62(0.51 ; 0.73)$ & $0.80(0.77 ; 0.83)$ & $0.78(0.76 ; 0.81)$ & - \\
\hline
\end{tabular}

$95 \%$ Confidence Interval in parentheses. (-) Impossible to estimate or not reported because of the small sample size and small variation in the dependent variable

represented by $\widehat{u_{1}}$ and $\widehat{u_{2}}$ are significant and show the expected sign in Eqs. (2) and (3). Firstly, $\widehat{u_{1}}$ in Eq. (2) indicates that educational attainments not attributable to parental antecedents positively (and significantly) affect to the probability of having a top occupation. Secondly, $\widehat{u_{1}}$ and $\widehat{u_{2}}$ in Eq. (3) indicate that attainments in education and occupation not attributable to parental antecedents influence descendants' SAH positively and also significantly, as the residuals of previous equations are significant at $99 \%$.

The results shown in Table 3 confirm the large and significant estimated effects of fathers' occupation on descendants' education, occupational category and SAH. Descendants of managers and professionals exhibit the highest probabilities of reaching higher education, top occupations and good health across all cohorts. Furthermore, descendants of unskilled worker fathers show lower probabilities of a higher education compared to descendants of skilled workers for all cohorts. This gap is even higher during the democracy period, although the total social gradient was significantly reduced during democracy as probabilities of having a higher educational level for children of managers, professionals, supporting 
workers and armed forces noticeably decrease for the last cohort. In fact, inequalities rose between the pre-war and the post-war cohort, but they started to decrease just after that point. The legacy of top occupations from father to children is also significant and persistent over time, and differences between children of managers and professionals and children of unskilled elementary workers hardly change after the war except for the democracy cohort, which shows a noticeably increased gap.

Regarding health, the most relevant finding is that the social gap in descendants' health inherited from the father decreased significantly across cohorts, except perhaps for the youngest cohort, although it is not possible to obtain reliable estimates due to the small sample size in this case. The probability of reporting a good health status for children of unskilled elementary workers increases from 0.31 (95\% confidence interval (CI) 0.14-0.48) for the oldest cohort to 0.49 (95\% CI 0.39-0.59) for those born during the period 1959-1975. For children of skilled workers, those probabilities increase from 0.51 (95\% CI $0.42-0.61$ ) to 0.68 (95\% CI $0.65-0.71$ ), respectively. Therefore, children of both skilled and unskilled workers significantly improved their probability of reporting good health across time. Nevertheless, children of managers or midlevel professionals show probabilities ranging from 0.98 (95\% CI $0.98-0.99$ ) to 0.97 (95\% CI 0.96-0.98). Consequently, discrimination against lowest level workers persists over time.

The influence of the mother on descendants' outcomes is more limited. The effects on education show that mothers in top occupations had more educated children in the first and the last cohorts, but no significant differences are found in the war and post-war and Stabilization cohorts. It is worth noting that, for all cohorts, children whose mother is a homemaker show a higher probability of attaining a higher educational level compared to those with skilled and unskilled elementary working mothers. However, our models do not find significant effects on descendants' occupation.

Homemaker mothers also seem to exert some protection effect on their descendants' health, at least compared to those classified as skilled or unskilled elementary workers. Children of women in top occupations, however, show the highest probabilities of having good health. This gradient remains stable across cohorts, at least until democracy. Again, we have not reported the estimated probabilities for Eq. (3) for the cohort under democracy due to its small sample size (only 442 individuals) and also to the low variability in SAH (only 17 out of the 442 said their health is not good).

\section{Discussion}

Our results clearly indicate that parental occupation (as a measure of parental SES), has a significant impact on the health of children who become adults aged from 28 to 86 . These results are consistent with previous studies which focused on elder Spaniards [11, 18, 21]. Once we control for the indirect effects of social circumstances (pathway hypothesis), we prove that there has been a direct impact of early-life conditions on individuals' health. Besides, this effect is persistent through cohorts and generations.

Fathers and mothers seem to exert different influences, with the influence of the mother's status on children's achievements being notoriously lower. The same result was found by Tubeuf and Jusot [11]. The higher the socioeconomic level associated with the father's occupation, the more likely the individual will be more educated, healthier and occupy a top job, and these effects persist over time. We can also see a social gradient between individuals depending on their mothers' occupation, but in this case children of homemakers also have an advantage over the children of those mothers at the bottom of the occupational ranking, at least with respect to education and health. This fact could be due to that mother homemakers form a mixed group, which includes women with low qualification but also highly educated women who do not work (because of family obligations or any other reasons). While father's occupation reflects in most of the cases his educational background, the same is not true for mothers.

Regarding health, the positive influence of mothers as homemakers has been noted in other studies, for instance, to child obesity [27]. This might be due to the value that mothers' exclusive dedication to the health of their children provides. However, the estimated coefficients in this case might also be reflecting a problem of multicollinearity given that some mothers are homemakers because the husband's high SES generates enough income to support the family. Nevertheless, as we did not find any significant influence of mothers' occupation on the probability for children to have a top occupation, we conclude that this is not a serious problem in our case.

Moreover, the inheritage effect for occupational status found in this paper has been previously shown for other countries [28, 29] and also for Spain [30], and indicate that occupational stratification flows from one generation to the next. Also, we have found a positive and significant influence of individuals' economic situation on their self-reported health, similarly to what other studies proved for several European countries [31].

Social inequalities in educational attainment linked to fathers' SES between the top and the bottom of the social scale seem to have grown between the pre-war and the post-war cohorts, but they started to decrease from the Stabilization Plan cohort. However, differences in educational attainment between descendants of unskilled and skilled workers not only are visible across time, but they seem to have widened under democracy. This is an 
unexpected result, as education grants were widely promoted over this period. Lastly, the health gap between the children of unskilled and skilled workers has significantly decreased since the Stabilization Plan cohort. This reduction in health inequalities could possibly be related, at least for the third cohort, to the reform of the social security system covering health care for workers and their families (Ley de Bases de la Seguridad Social, 1963). Our results suggest that health inequalities due to the legacy effect have declined more than inherited educational and occupational inequalities over time.

An advantage of this study is its large sample and unusually detailed information on household income and wealth. Since the design of the survey gave more weight to high SES households, we were better able than previous studies to track the legacy of the most privileged parents to their offspring. However, there are some limitations linked to the dataset. The question on parental occupation in the survey refers to the job held during a parent's active life, not during the respondent's childhood. Fortunately for our purposes, labour mobility in Spain traditionally has been extremely limited, so we can assume that the occupation reported in the survey is a decent proxy. We also lack information on parental education and income; thus we are unable to incorporate the educational persistence hypothesis in our first equation, despite the fact that Spain is known to be one of the OECD countries where this persistence is most pronounced [32]. Lastly, neither could we incorporate parental health status into our model. Another possible bias is selection by mortality. We only observe the survivors, who may have been less affected by poor inheritance. This would be a downward bias, therefore, and the real effects of parental legacy might be even greater than those we have estimated. Moreover, Eqs. (1) and (2) do not take into account that individuals' health may affect educational and job attainment, as the reverse causality hypothesis points out. The SAH equation also omits relevant variables not collected in the survey, along with other unobservable heterogeneity. The connections between education and health are not so simple in real life as in the model [33]. Furthermore, it may be that not only occupation but also job security affects health, although this phenomenon does not seem as important in Spain as elsewhere [34, 35].

The selection of the sample may also be seen as a limitation of the study. However, it will hardly affect our results, since the proportion of people under 28 years is quite low (1.77\% of the sample). Furthermore, people aged over 86 account for only $0.81 \%$ of the sample and many of them are living in their descendants' homes. In the EFF, more than a half of the sample of people aged 87 or older are neither the reference person nor his/her partner.
The confusion of the age effect with the cohort effect is also a potential limitation. Individuals in our sample who were born in the post-war period are aged from 45 to 72, and the pre-war cohort is older than 66. Most of the individuals belonging to cohorts under democracy (28-33 years old) are younger at the time of the survey than cohorts of the Stabilization Plan period (28-51 years old), as the timespan of the survey is only 8 years. Thus, there are no persons in the sample born under democracy older than 33 , and therefore we cannot compare older persons born under Franco's dictatorship and older persons born under democracy. Age at the time of the survey only overlaps for adjacent cohorts. We have not reported the estimated probabilities for Eq. (3) for the cohort under democracy because the sample size is small and the variability in SAH is very low. Future research will be able to follow these cohorts as they grow older, since latent health problems may surface later in life due to poor living conditions in childhood. Other than that, it seems clear that the children of the socially privileged, at least until the democracy cohorts, maintain privileges in health during adulthood.

\section{Conclusions}

By using a large data sample, which includes unusually detailed information on household income and wealth and covers cohorts of adults born in different decades, we conclude that parental occupation has a significant direct impact on individuals' health. Socioeconomic status is transmitted from one generation to the next through different paths, but adult's health is, to a certain extent, a consequence of the family socioeconomic position during childhood.

Although health inequalities in adult Spaniards are partly due to socioeconomic circumstances in childhood, great progress has been made during the twentieth century, so that the impact of parental SES on individuals' health has been significantly tempered for those at the bottom of the social scale. Nevertheless, since discrimination against unskilled workers' descendants persists over time, more efforts focused on the improvement of living conditions for most socioeconomically disadvantaged are needed in order to further reduce social inequalities in health. This is an important message for social policy makers: actual social policies may have persistent effects and are potentially useful to promote health of generations ahead.

\section{Abbreviations}

Cl: Confidence interval; EFF: Spanish Survey of Household Finances (Encuesta Financiera de las Familias); ISCO: International Standard Classification of

Occupations; OECD: Organization of Economic Cooperation and

Development; SAH: Self-assessed health; SES: Socioeconomic status; SHARE: Survey of Health, Aging and Retirement in Europe 


\section{Acknowledgments}

We are grateful to Mauro Hernández for his comments on the text and his revision of all language related-issues.

\section{Funding}

This study was supported by the research project ECO2013-48217. Plan Nacional de Investigación Orientada a los Retos de la Sociedad 2014-2016, http://invesfeps.ulpgc.es/en. This fuding has not determined in any way the design of the study, the collection, analysis, interpretation of data or writing of the manuscript, which is the authors' exclussive responsibility.

\section{Availability of data and materials}

The data that support the findings of this study are available from Bank of Spain, but restrictions apply to the availability of these data, which were used under license for the current study, and so are not publicly available. Data are however available from the authors upon reasonable request and with permission of Bank of Spain.

\section{Authors' contributions}

JP, BLV and RUG discussed the motivation and design of the research. Specifically, JP has contributed to the conception and motivation of the study, and to the collection and preparation of the data. BLV has contributed to the design of the research. JP and BLV have contributed to the estimation process and the interpretation of results. RUG has contributed to the motivation of the study, selection of contents and elaboration of the discussion. The three authors have also been involved in drafting and revising the manuscript, have given final approval to the version to be published and have agreed to be accountable for all aspects of the research related to accuracy and integrity of any part of the work. The three authors read and approved the final manuscript.

\section{Competing interests}

The authors declare that they have no competing interests.

\section{Consent for publication}

Not applicable.

\section{Ethics approval and consent to participate}

Not applicable.

\section{Author details}

'Department of Quantitative Methods for Economics and Management, University of Las Palmas de Gran Canaria, Las Palmas de Gran Canaria, Spain. ${ }^{2}$ Department of Public Finance, School of Economics, Complutense University of Madrid, Campus de Somosaguas s/n, 28223 Pozuelo de Alarcón, Spain.

Received: 20 July 2016 Accepted: 23 December 2016

Published online: 05 January 2017

\section{References}

1. Peck MN. The importance of childhood socioeconomic group for adult health. Soc Sci Med. 1994;39(4):553-62.

2. Wannamethee SG, Whincup PH, Shaper G, Walker M. Influence of fathers' social class on cardiovascular disease in middleaged men. Lancet. 1996:348:1259-63.

3. Davey Smith G, Hart C, Blane D, Gillis C, Hawthorne V. Lifetime socioeconomic position and mortality: prospective observational study. BMJ. 1997;314:547-52.

4. Davey Smith G, McCarron P. Okasha M, McEwen J. Social circumstances in childhood and cardiovascular disease mortality: prospective observational study of Glasgow University students. J Epidemiol Community Health. 2001;55:340-1.

5. Case A, Lubotsky D, Paxson C. Economic Status and Health in Childhood: The Origins of the Gradient. Am Econ Rev. 2002;92(5):1308-34.

6. Kuh D, Hardy R, Langenberg C, Richards M, Wadsworth MEJ. Mortality in adults aged 26-54 years related to socioeconomic conditions in childhood and adulthood: post war birth cohort study. BMJ. 2002;325:1076-80.

7. Pensola TH, Valkonen T. Effect of parental social class, own education and social class on mortality among young men. Eur J Public Health. 2002;12:29-36.

8. Case A, Fertig A, Paxson C. The lasting impact of childhood health and circumstance. J Health Econ. 2005;24(2):365-89.
9. Currie J, Goodman J. Parental Socioeconomic Status, Child Health, and Human Capital. In: Peterson P, Baker E, McGaw B, editors. International Encyclopedia of Education. Elsevier; 2010. p. 253-9. http://scholar.harvard. edu/files/joshuagoodman/files/parentalses.pdf.

10. Trannoy A, Tubeuf S, Jusot F, Devaux M. Inequality of opportunities in health in France: a first pass. Health Econ. 2010;19(8):921-38.

11. Tubeuf S, Jusot F. Social health inequalities among older Europeans: the contribution of social and family background. Eur J Health Econ. 2011;12:61-77.

12. Currie J, VogI T. Early-life health and adult circumstance in developing countries. Annu Rev Econo. 2012;5:1-36.

13. Jones A, Rice N, Rosa-Dias P. Quality of schooling and inequality of opportunity in health. Empir Econ. 2012;42(2):369-94.

14. Tubeuf S, Jusot F, Bricard D. Mediating role of socioeconomic factors and lifestyles in the relationship between early-life conditions and health: Evidence from the 1958 British cohort. Health Econ. 2012;21 Suppl 1:129-50.

15. Jablonska B, Lindblad F, Östberg V, Lindberg L, Rasmussen F, Hjern A. A national cohort study of parental socioeconomic status and non-fatal suicidal behaviourthe mediating role of school performance. BMC Public Health. 2012;12:17.

16. Koffijberg H, Adami J, Buskens E. Palme. Parental education and adult health outcomes: a cohort study examining disease-specific effects of education levels using Swedish nationwide registries across two generations. Longit Life Course Stud. 2012:3(3):298-311.

17. Bhalotra S, Rawlings $S$. Gradients of the intergenerational transmission of health in developing countries. Rev Econ Stat. 2013;95(2):660-72.

18. Bricard D, Jusot F, Trannoy A, Tubeuf S. Inequality of opportunities in health and the principle of natural reward: evicence for European countries. In: Rosa-Dias P, O'Donnell O, editors. Research on Economic Inequality, vol. 21. UK: Emerald Group Publishing Limited; 2013. p. 335-70.

19. Jusot F, Tubeuf S, Trannoy A. Circumstances and Effort: How important is their correlation for the measurement of inequality of opportunity in health? Health Econ. 2013;22(12):1470-95.

20. Eriksson T, Pan J, Qin X. The intergenerational inequality of health in China. China Econ Rev. 2014:31:392-409.

21. Flores M, Kalwij A. The associations between early life circumstances and later life health and employment in Europe. Empir Econ. 2014:47(4):1251-82.

22. Lindahl M, Lundberg E, Palme M, Simeonova E. Parental Influences on Health and Longevity: Lessons from a Large Sample of Adoptees. NBER Working Paper No. 21946. January 2016.

23. Wadsworth MEJ. Early life hypothesis. In: Marmot M, Wilkinson R, editors. Social Determinants of Health. Oxford: Oxford University Press; 1999. p. 44-63.

24. Lerman PM. Fitting segmented regression models by grid search. Appl Statist. 1980;29:77-84.

25. Ai C, Norton EC. Interaction terms in logit and probit models. Econ Lett. 2003:80:123-9.

26. Gourieroux C, Monfort A, Renault E, Trognon A. Generalised residuals. J Econometrics. 1987:34:1-2.

27. García E, Labeaga J, Ortega C. Maternal Employment and Childhood Obesity in Spain. Fundación de Estudios de Economía Aplicada (FEDEA) Working Papers n 17; 2006.

28. Carmichael F. Intergenerational mobility and occupational status in Britain. Appl Econ Lett. 2000;7:391-6.

29. Di Pietro G, Urwin P. Intergenerational mobility and occupational status in Italy. Appl Econ Lett. 2003;10:793-7.

30. Pascual M. Intergenerational income mobility: The transmission of socioeconomic status in Spain. J Policy Model. 2009;31:835-46.

31. Mackenbach JP, Martikainen P, Looman CW, Dalstra JA, Kunst AE, Lahelma E. The shape of the relationship between income and self-assessed health: an international study. Int J Epidemiol. 2005;34(2):286-93.

32. Organization for Economic Co-operation and Development. A family affair Intergenerational social mobility across OECD countries. In: OECD. Economic Policy Reforms 2010. Going for Growth. Paris: OECD; 2010. p. 181-198.

33. Cutler D, LLeras-Muney A. Education and Health: Insights from International Comparisons. National Bureau of Economic Research (NBER) Working Papers 17738; 2012.

34. Jusot F, Grignon M, Dourgnon P. Access to psycho-social resources and health: exploratory findings from a survey of the french population. Health Econ Policy Law. 2008;3(4):365-91.

35. Laszlo KD, Pikhart H, Kopp MS, Bobak M, Pajak A, Malyutina S, et al. Job insecurity and health: a study of 16 European countries. Soc Sci Med. 2010;70(6):867-74. 